\title{
International Conference On Modern research
}

\section{in Engineering,Technology and Science}

\section{9-31 March Prague, Czech Republic}

\section{Aqueous Extraction of Blue Dye from Butterfly Pea Flower: An Optimization Study Using Response Surface Methodology}

\author{
M. Rajan', S.K.A Mudalib ${ }^{1}$ and I. Izirwan' ${ }^{1}$ \\ ${ }^{1}$ Faculty of Chemical and Natural Resources Engineering, Universiti Malaysia Pahang, Lebuhraya Tun Razak, \\ 26300 Gambang, Pahang, Malaysia.
}

\begin{abstract}
:
Natural colorant enhances the attractiveness and physical appearances of various food, confectionery and beverages. A healthy diet style of less dependency on synthetic colorants by replacing with the natural colorants may reduce the development of food allergies and suspicious illness of cancer development. Anthocyanin as the targeted pigment compound in butterfly pea flower was extracted by maceration method. The objectives of this research are to determine the optimum extraction conditions and to obtain the yield of the blue dye. Parameters, namely solid to liquid ratio $(1: 20,1: 30$, $1: 40,1: 50$ and 1:60 g/ml), extraction time (30, 40, 60,70 and $90 \mathrm{~min})$ and temperature $(30,40,60,70$ and $90^{\circ} \mathrm{C}$ ) were investigated by one factor at time time method (OFAT). The blue dye was characterized by gas chromatography-mass spectrometry (GC-MS) and Ultraviolet-visible spectroscopy (UV-Vis). After completing the parameters screening, design of experimental (DOE) and process optimization were utilized by response surface methodology (RSM) with central composite rotatable design (CCRD). The developed mathematical model was fit well with the experimental results for all the three manipulated variables. The optimum extraction condition of blue dye was $42.6 \%$ yield at $60{ }^{\circ} \mathrm{C}$ of extraction temperature, $1: 30 \mathrm{~g} / \mathrm{ml}$ solid to liquid ratio and 60 minutes of extraction time.
\end{abstract}

Keywords: Butterfly Pea Flower, Extraction, Response Surface Methodology, Optimization, Blue Dye. 